\title{
Patients' recall of diagnostic and treatment information improves with use of the Pain Explanation and Treatment Diagram in an outpatient chronic pain clinic
}

\author{
Hillel M Finestone MD CM${ }^{1}$, Matthew M Yanni $\mathrm{BSc}^{2}$, Catherine J Dalzell $\mathrm{PhD}^{3}$
}

\begin{abstract}
HM Finestone, MM Yanni, CJ Dalzell. Patients' recall of diagnostic and treatment information improves with use of the Pain Explanation and Treatment Diagram in an outpatient chronic pain clinic. Pain Res Manag 2015;20(3):145-151.
\end{abstract}

BACKGROUND: To maximize the benefit of therapies, patients must understand their condition, recall treatment suggestions and comply with treatments. The Pain Explanation and Treatment Diagram (PETD) is a one-page worksheet that identifies risk factors (health-related habits, sleep, exercise, ergonomics and psychosocial factors) involved in chronic pain. Clinician and patient complete the PETD together, and the clinician notes recommended treatments and lifestyle changes.

OBJECTIVES: To examine the effect of use of the PETD on patient recall of diagnostic and treatment information on the sheet.

METHODS: The present study was a cross-sectional analysis. Patients with chronic musculoskeletal pain seen by one physiatrist at an outpatient pain clinic in a university-affiliated hospital between 2009 and 2012 (all of whom received the PETD) were eligible. A structured telephone interview lasting approximately $1 \mathrm{~h}$ was used to determine recall of PETD diagnostic and treatment information.

RESULTS: Of the 84 eligible patients, 46 were contacted and 29 completed the telephone interview. Participants recalled an average of $12.2 \%(95 \% \mathrm{CI}$ $7.8 \%$ to $17.4 \%$ ) of items without prompting and $48.5 \%$ (95\% CI $42.0 \%$ to $53.5 \%)$ when prompted. Participants who referred to the PETD at home $(n=13)$ recalled significantly more items than those who did not $(n=15)$ ( $17.6 \%$ [95\% CI $11.1 \%$ to $23.9 \%$ ] versus $5.2 \%$ [ $95 \%$ CI $3.0 \%$ to $14.5 \%$ ], $\mathrm{P}=0.004$ ); when prompted, the rates increased to $54.3 \%$ (95\% CI $48.3 \%$ to $61.2 \%$ ) and $41.2 \%$ (95\% CI $34.7 \%$ to $50.7 \%$ ), respectively ( $\mathrm{P}=0.032$ ).

CONCLUSIONS: The PETD is a promising, feasible and inexpensive tool that can improve patients' recall of diagnostic- and treatment-related information.

Key Words: Chronic pain; Musculoskeletal; Pain management; Patient communication; Patient recall

\author{
Les patients se souviennent mieux de \\ l'information diagnostique et thérapeutique \\ grâce au diagramme d'explication et de traitement \\ de la douleur dans une clinique ambulatoire de \\ douleur chronique
}

\begin{abstract}
HISTORIQUE : Pour maximiser les bienfaits des traitements, les patients doivent comprendre leur état, se souvenir des suggestions thérapeutiques et respecter les traitements. Le diagramme d'explication et de traitement de la douleur (DETD) est une feuille d'une page qui indique les facteurs de risque (habitudes liées à la santé, sommeil, exercice, ergonomie et facteurs psychosociaux) de douleur chronique. Le clinicien et le patient remplissent le DETD ensemble, et le clinicien consigne les traitements et les modifications au mode de vie recommandés.

OBJECTIFS : Examiner l'effet de l'utilisation du DETD sur le souvenir que les patients ont de l'information diagnostique et thérapeutique consignée.

MÉTHODOLOGIE : Les patients ayant des douleurs musculosquelettiques chroniques vus par un physiatre à la clinique ambulatoire de douleur d'un centre hospitalier universitaire entre 2009 et 2012 (qui avaient tous reçu un DETD) étaient admissibles à cette étude transversale. Une entrevue téléphonique structurée d'environ une heure a permis de déterminer à quel point les patients se souvenaient de l'information diagnostique et thérapeutique inscrite sur le DETD.

RÉSULTATS : Sur les 84 patients admissibles, 46 ont été joints, et 29 ont effectué l'entrevue téléphonique. Les participants se souvenaient en moyenne de $12,2 \%$ des points ( $95 \%$ IC 7,8 \% à 17,4\%) spontanément et de $48,5 \%$ des points (95\% IC 42,0 \% à 53,5\%) avec de l'aide. Les participants qui consultaient le DETD à la maison $(\mathrm{n}=13)$ se souvenaient de beaucoup plus de points que ceux qui ne le consultaient pas $(\mathrm{n}=15)(17,6 \%$ [95 \% IC $11,1 \%$ à 23,9 \%] par rapport à 5,2 \% [95 \% IC 3,0 \% à 14,5\%], P=0,004). Lorsqu'ils avaient de l'aide, le taux passaient à $54,3 \%$ (95 \% IC 48,3 \% à $61,2 \%)$ et à 41,2\% (95\% IC 34,7\% à 50,7\%), respectivement ( $\mathrm{P}=0,032)$. CONCLUSIONS : Le DETD est un outil prometteur, faisable et peu coûteux qui peut améliorer le souvenir qu'ont les patients de l'information liée au diagnostic et au traitement.
\end{abstract}

support) improves clinical outcomes in adult patients with a variety of diseases (5-7). Verbal teaching and discussions - physicians' most common methods of communication - were found to be least effective $(8,9)$. However, there is a dearth of high-quality studies exploring psychoeducational interventions (10), which involve such strategies as use of simple communication that defines diagnoses, prognoses and treatment, and use of a personalized plan (10). Personalized information that recognizes variations in patient experience is more likely to improve outcomes (11). Recall may be improved when interventions are tailored to the individual patient's needs and circumstances (12-14).

Patients' recall of risk factors in the context of informed consent to surgery $(15-20)$ or clinical trials (21) is often discouraging. Reported recall rates in other contexts have varied from $61 \%$ for a plan of action delivery (eg, print, audiotapes and videotapes) for patient education has shown that psychoeducational care (education, exercise and psychosocial
${ }^{1}$ Élisabeth Bruyère Hospital; ${ }^{2}$ University of Ottawa; ${ }^{3}$ Bruyère Research Institute, Bruyère Continuing Care, Ottawa, Ontario Correspondence: Dr Hillel M Finestone, Department of Physical Medicine and Rehabilitation, Élisabeth Bruyère Hospital, Bruyère Continuing Care,

43 Bruyère Street, Ottawa, Ontario K1N 5C8. Telephone 613-562-6094, fax 613-562-6312, e-mail hfinestone@bruyere.org
OPEN ACCESS

This open-access article is distributed under the terms of the Creative Commons Attribution Non-Commercial License (CC BY-NC) (http:/ creativecommons.org/licenses/by-nc/4.0/), which permits reuse, distribution and reproduction of the article, provided that the original work is properly cited and the reuse is restricted to noncommercial purposes. For commercial reuse, contact support@pulsus.com 


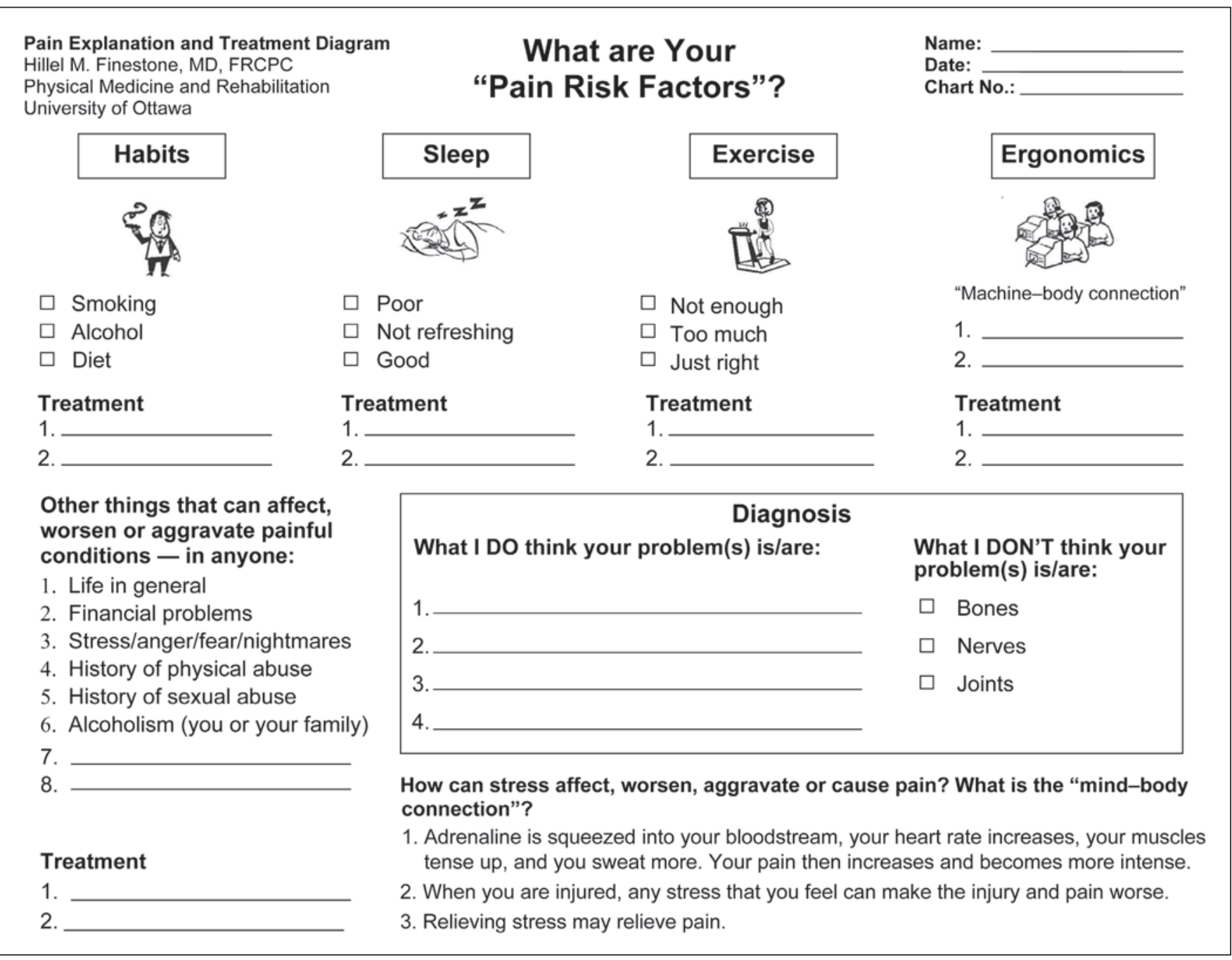

Figure 1) Pain Explanation and Treatment Diagram

to $90 \%$ for the main problem during face-to-face encounters with 10 general practitioners (22), $25 \%$ recall of information regarding reduction mammoplasty (23), 29\% recall of four instructions provided by general practitioners (24) and 39\% of oncology patients who recalled information on an audiotape (25).

The experience of pain can be difficult to communicate. The European CHANGE PAIN group described a simple graphical tool that enables the patient to convey pain severity and how the pain affects daily life tasks (26). Building on the principles of this tool and the concept of pain risk factors (2), the principal author developed the Pain Explanation and Treatment Diagram (PETD). The purpose of the PETD is to educate patients with chronic musculoskeletal pain regarding their current diagnoses and pain risk factors, provide an action plan and assist recall. A pilot study of the tool resulted in positive findings (27).

We performed a cross-sectional study among patients experiencing chronic musculoskeletal pain who received the PETD. Our objective was to examine the effect of physician/patient use of the PETD on recall of the diagnostic and treatment information on the worksheet.

\section{METHODS}

Pain Explanation and Treatment Diagram

The PETD (Figure 1) is a one-page worksheet that outlines the primary risk factors involved in chronic pain: health-related habits, sleep, exercise, ergonomics (eg, poor work station, work repetitiveness and/or intensity) and psychosocial factors. These pain risk factors may predispose to, cause or exacerbate painful musculoskeletal conditions including back or neck pain, and fibromyalgia syndrome $(2,27,28)$. At the end of the consultation, the clinician completes the form with the patient, systematically explaining the role of these factors and suggesting treatments and lifestyle changes that correspond to the patient's individual situation. The diagnoses are documented, and the clinician's response to inaccurate pain beliefs (eg, "The x-ray changes in the joints of your neck are probably not as important as the pain coming from your muscles and ligaments" or "I don't think you have a nerve injury") are recorded. The PETD takes approximately $10 \mathrm{~min}$ to review and complete. The form is completed in duplicate (using simple carbon paper), and patients are encouraged to consult it in the future if they wish to be reminded about what transpired during their consultation and the recommended treatments. They can also show it to their other involved health care professionals.

Eligibility and recruitment

The present study involved outpatients referred for a consultation regarding their chronic musculoskeletal pain in the physical medicine and rehabilitation department of a university-affiliated hospital in southern Ontario. Eligible patients were seen by the principal author, a physiatrist, between July 2009 and June 2012, were $\geq 18$ years of age, and could speak and read English. Patients were usually seen two to four times over a one-year period. In all cases, a PETD worksheet was completed during the first session and a copy given to the patient.

Eligible patients were initially telephoned by a summer research student (who was not otherwise involved in the study). The names of 


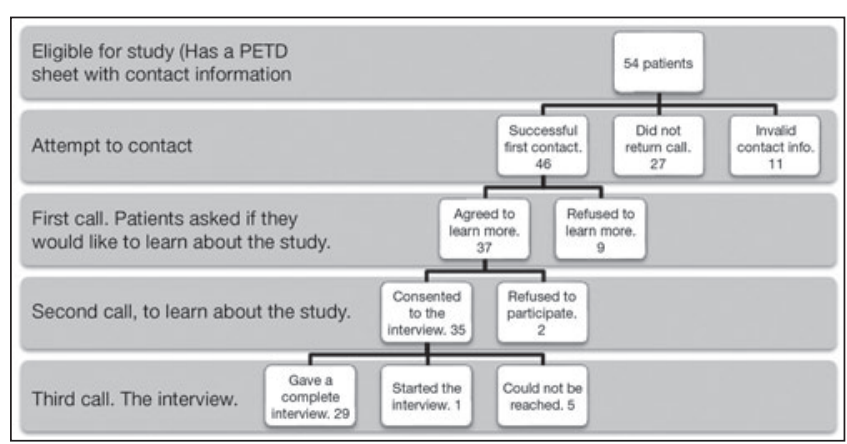

Figure 2) Patient flow chart. PETD Pain Explanation and Treatment Diagram

those who indicated a willingness to hear more about the study were passed on to a research assistant (RA). The RA telephoned these patients and explained the study research objectives, provided information regarding participation and asked whether the patient would be willing to participate in a structured interview lasting approximately $1 \mathrm{~h}$. If the patient provided consent, a date was set for the telephone interview, to take place at his or her convenience. The interviews were conducted during the summer of 2012. All interviews were conducted by the RA.

The hospital research ethics board approved the study.

\section{Interview}

The participants were first asked whether they had any recollection of the PETD (Appendix 1). If they remembered it, they were asked where they kept it and how often they referred to it.

Consulting a copy of the participant's PETD, the RA then systematically asked participants what the doctor believed their problems were, what other conditions in their life could affect their pain and what treatments were recommended (if any). Recall of specific information was divided into unprompted and prompted recall. Unprompted recall was assessed by asking patients to list as much information as they could remember from the PETD without prompting them about each subheading. Prompted recall was assessed by asking the patients to list as much information they could remember from each category as it was mentioned by the interviewer (eg, "What did Dr X say about your level of exercise?," "What did Dr X recommend for your sleep problems?"). The RA recorded the number of correct responses in each category compared with the information documented on the participant's PETD. Participants' responses were considered to be correct if they restated what was written on the PETD or expressed what was written in their own words. For example, if it was noted on the PETD that sleep was poor and the participant stated "The doctor said I was not sleeping well”, this was considered to be a correct answer.

Patient age, level of education, date of the interview and the date of the initial appointment with the physiatrist were noted.

\section{Statistical analysis}

The primary outcome of the study was recall of items on the PETD. Summary statistics of recall were calculated for the total number of items on the worksheet and for each diagnostic category. Recall was tested against time elapsed (in days) between the initial consultation and the interview.

The test of the effect of PETD use on recall used a beta-binomial random effects model with patient as random effect and individual treatment item as response $(29,30)$. The analysis was performed using $\mathrm{R}$ software (31) with a package written by Bolker et al (32). The P values in the present article for the effect of PETD use were derived from this model; in the present case, $n=585$ (number of items), with 28 clusters (number of patients).

Overall CIs were calculated on the basis of recall rate per person using a bootstrap CI. Given the small number of items in each category, CIs for individual categories on the PETD were calculated by aggregating across patients and using the total number of recalled
TABLE 1

Number of diagnostic and treatment items on the Pain Explanation and Treatment Diagram per patient, according to area

\begin{tabular}{lcc}
\hline Area & Mean number of items & Range \\
\hline Habits & 1.1 & \\
Diagnosis & 0.8 & $0-3$ \\
Treatment & 1.1 & $0-3$ \\
Sleep & 1.1 & \\
Diagnosis & & $0-3$ \\
Treatment & 0.9 & $0-2$ \\
Exercise & 1.7 & \\
Diagnosis & & $0-2$ \\
Treatment & 1.1 & $1-4$ \\
Ergonomics & 1.0 & \\
Diagnosis & & $0-2$ \\
Treatment & 2.6 & $0-2$ \\
Psychosocial & 1.2 & \\
Diagnosis & & $0-7$ \\
Treatment & 6.8 & $0-4$ \\
Overall & 5.8 & $2-11$ \\
Diagnosis & & $2-9$ \\
Treatment & & \\
\hline
\end{tabular}

items divided by the number of diagnostic and treatment items. No meaningful cluster effect was found at this level of analysis.

\section{RESULTS}

A total of 150 patients were evaluated between July 2009 and June 2012. The PETD was administered to 84 patients with chronic painful conditions. The 66 remaining patients had more defined musculoskeletal pain diagnoses, such as lateral epicondylitis or lumbosacral radiculopathy, and administration of the PETD was not believed to be appropriate in these cases.

Of the 84 patients who were eligible for the study, 27 did not return the initial telephone call, and contact information was invalid for 11 (Figure 2). Forty-six patients were successfully contacted, nine of whom believed the $1 \mathrm{~h}$ interview would be too long. Of the remaining 37 patients who agreed to learn more about the study, 35 consented to be interviewed: 29 completed the interview, five could not be reached (repeated calls were unanswered), and one ended the call after the first few questions.

The 29 participants ranged in age from 22 to 75 years (median 54 years). Most $(n=22)$ had some postsecondary education. There were 21 women and seven men; in one case, sex was not recorded.

The participants had, on average, 20 informational items (range nine to 29) on their PETD worksheet. All of the participants had items in at least two of the five risk factor areas of the PETD (ie, habits, sleep, exercise, ergonomics and psychosocial factors), with a mean of 4.3 areas per patient. Table 1 shows the average number of diagnostic and treatment items per patient for each area of the PETD and overall. The area with the highest average number of items was diagnosed psychosocial factors. Exercise as a treatment modality was recommended for all participants.

One patient had a very high recall rate although he declared no further use of the PETD after the initial consultation. Because the results did not change substantially and more stable parameter estimates were obtained with omission of the outlier, the results are reported without the data for this patient.

\section{Recall of information}

The participants recalled an average of $12.2 \%$ (95\% CI $7.8 \%$ to $17.4 \%$ ) of the items on their PETD without prompting and $48.5 \%$ (95\% CI $42.0 \%$ to $53.5 \%$ ) when prompted. Table 2 shows the percentage of diagnostic and treatment items recalled with prompting. Recall 


\begin{tabular}{|c|c|}
\hline Area & Mean $\%$ of items recalled $\left(95 \% \mathrm{Cl}^{*}\right)$ \\
\hline \multicolumn{2}{|l|}{ Habits } \\
\hline Diagnosis & $68.8(52.7-84.8)$ \\
\hline Treatment & $77.3(59.8-94.8)$ \\
\hline \multicolumn{2}{|l|}{ Sleep } \\
\hline Diagnosis & $74.2(58.8-90.0)$ \\
\hline Treatment & $52.3(35.1-69.5)$ \\
\hline \multicolumn{2}{|l|}{ Exercise } \\
\hline Diagnosis & $69.2(51.5-87.0)$ \\
\hline Treatment & $60.0(46.4-73.6)$ \\
\hline \multicolumn{2}{|l|}{ Ergonomics } \\
\hline Diagnosis & $25.8(10.4-41.2)$ \\
\hline Treatment & $43.3(25.6-61.1)$ \\
\hline \multicolumn{2}{|c|}{ Psychosocial factors } \\
\hline Diagnosis & $64.5(53.7-75.2)$ \\
\hline Treatment & $55.9(39.2-72.8)$ \\
\hline \multicolumn{2}{|l|}{ Overall } \\
\hline Diagnosis & $61.2(53.0-69.4)$ \\
\hline Treatment & $58.2(49.7-66.7)$ \\
\hline
\end{tabular}

${ }^{*} \mathrm{Cls}$ for total items were calculated taking cluster effects into account. For individual categories, the $\mathrm{Cl}$ was calculated in the usual way for a binomial proportion because no cluster effects were apparent with the small numbers involved

of the ergonomics diagnosis section was substantially lower than that of the other diagnosis sections.

Recall regarding inaccurate information and inaccurate pain beliefs was poor. Twenty-three participants $(79.3 \%)$ had at least one incorrect idea about their chronic pain, and 18 participants $(62.1 \%)$ had three. However, only three participants remembered any aspect of this discussion.

Recall as a function of PETD use: Because categories of PETD use at home were numerous and difficult to rank (eg, a couple of times after the office visit, monthly for a period of time, weekly), use was recoded as a binary variable: Referred to/Did not refer to. Participants who could not remember viewing the PETD or who reported not specifically looking at it after the consultation were assigned 'Did not refer to' $(n=15[55 \%])$. The remaining participants $(n=13)$, who referred to the PETD at least once after their initial consultation, were classified as having referred to the PETD.

When not prompted, participants who referred to the PETD recalled significantly more items on their PETD than those who did not refer to the worksheet $(17.6 \%$ [95\% CI $11.1 \%$ to $23.9 \%$ ] versus $5.2 \%$ [ $95 \%$ CI $3.0 \%$ to $14.5 \%$ ]; $\mathrm{P}=0.004)$. When prompted, rates increased to $54.3 \%$ (95\% CI $48.3 \%$ to $61.2 \%$ ) and $41.2 \%$ (95\% CI $34.7 \%$ to $50.7 \%)$, respectively $(\mathrm{P}=0.032)$. Table 3 shows percentage recall with and without prompting, as well as for diagnostic and treatment items in the five PETD areas. The straight difference in proportions is presented, as well as an estimated effect size (Appendix 2) (33).

The proportion of items recalled without prompting did not differ statistically with the number of items $(\mathrm{P}=0.56$ in a linear regression).

Time elapsed: There was no evidence that the recall rate depended on the time elapsed since the initial consultation with the physiatrist (linear regression using unprompted recall, $\mathrm{P}=0.357$; using prompted recall, $\mathrm{P}=0.19)$. Participants who referred to the PETD at home and those who did not had the same pattern of elapsed time between the date that the PETD was completed and the study interview (MannWhitney test, $\mathrm{P}=0.464)$. Figure 3 shows the unprompted recall rate

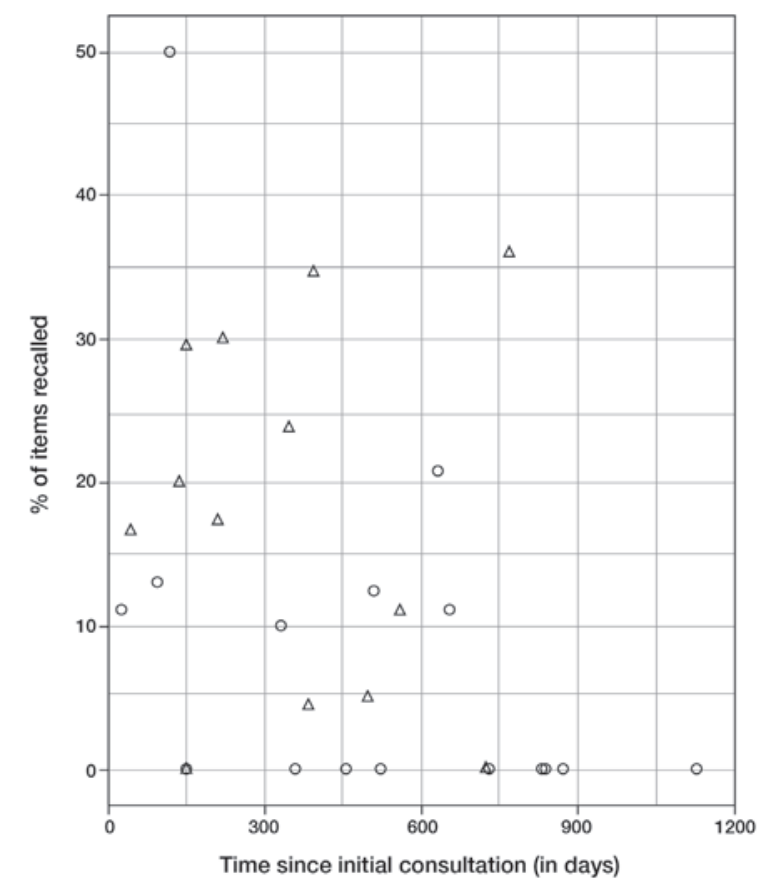

Figure 3) Unprompted recall according to time since initial consultation. $\Delta$ Pain Explanation and Treatment Diagram referred to at home, o Pain Explanation and Treatment Diagram not referred to at home

by time since the initial consultation according to PETD use. Those who referred to the PETD at home recalled more items than those who did not.

\section{DISCUSSION}

Pain management education has been shown to ameliorate patients' pain symptoms (14) and to enhance their pain beliefs (34) and selfefficacy $(14,34,35)$. Brief tools that can be administered in-office are required to meet this need. A search of the English-language literature using the keywords "pain management," "tools," "patient education" and "chronic pain therapy/patient education" did not identify any articles describing a tool similar to our one-page PETD. Watson and McKinstry (10) noted the "dearth of high-quality studies exploring interventions incorporating psychological theory." Our results demonstrate how the PETD incorporates some of these educational initiatives, in a comprehensive manner.

Providing information that is simple, tangible, portable and individualized to the patient/situation is the most effective method of communicating medical information and ensuring retention $(5,12,15,20)$. The PETD helped educate patients with chronic musculoskeletal pain about their diagnoses and pain risk factors, and its use at home improved recall. The prompted recall rates were $54.3 \%$ for participants who referred to the PETD at home and $42.7 \%$ for those who did not. This compares favourably with previously reported rates among general practice, plastic surgery and oncology patients (22-25). Recall rates for the specific areas of the PETD were similar to those found in other studies of recall of diagnostic and treatment information $(11,36-39)$.

All of the participants completed a PETD worksheet during their first consultation with the physiatrist. This process - an organized, formal conceptualization of the patient's problem areas, diagnoses, treatments and pain beliefs - provided depth to the consultation and improved patients' recall. It also provided the patient with an action plan for selfmanaging pain risk factors. To maximize the effect of the PETD, the 
TABLE 3

Effect of Pain Explanation and Treatment Diagram (PETD) use after the initial consultation, as estimated from fitting a beta-binomial model $(n=28)^{*}$

\begin{tabular}{|c|c|c|c|c|c|}
\hline & \multicolumn{2}{|c|}{ \% Recall } & \multirow[b]{2}{*}{ Observed difference } & \multirow{2}{*}{$\begin{array}{c}\text { Effect size from beta- } \\
\text { binomial model }(95 \% \mathrm{Cl})\end{array}$} & \multirow[b]{2}{*}{$\mathbf{P}$} \\
\hline & PETD not referred to at home & PETD referred to at home & & & \\
\hline Unprompted recall (all items) & 5.2 (8.0 with outlier) & 17.6 & 12.4 & $12.5(4.2-21.5)$ & 0.004 \\
\hline Prompted recall (all items) & 41.2 (42.7 with outlier) & 54.3 & 13.1 & $11.6(1.0-22.2)$ & 0.032 \\
\hline Diagnostic items & 56.0 & 71.1 & 15.1 & $15.5(-1.5-31.8)$ & 0.074 \\
\hline Treatment items & 45.5 & 67.9 & 22.4 & $18.4^{\dagger}$ & 0.062 \\
\hline
\end{tabular}

*The beta-binomial model is a generalized linear model suitable for modelling clustered binary outcomes. The effect size is the estimated difference in the probability of recall under the beta-binomial model. This value is close to the observed difference in percentage use between the participants who referred to the PETD at home and those who did not. The Cls are derived from the likelihood function. The $P$ value comes from the Wald statistic (approximate t test for the estimated difference, using a SE from the likelihood function). The table was constructed from the reduced data set (after removal of the outlier's data). Significant results were also obtained with the full data set. ${ }^{\dagger}$ Fitting a beta-binomial model did not converge well for this case; thus, the Cl is not available

patient was asked to contemplate the connections between his or her pain and the pain risk factors discussed to develop strategies to cope with the pain or control the factors that exacerbate it. The patient's ability to refer to the PETD repeatedly over time is, therefore, an important feature that we believe contributes to the positive effect of the tool.

Despite the small sample size, the results show that the PETD augmented recall for all participants, with a prompted recall rate of $48.5 \%$. This means that patients administered the PETD after a physiatry consultation remembered almost one-half of the diagnostic and treatment information on the worksheet. Almost one-half (45\%) indicated that they referred to the PETD at least once after the consultation. Those who referred to the PETD recalled three times as many items as those who did not refer to it. Asking the patients about particular categories on the worksheet (prompting) had the effect of jogging their memories. When the participants were prompted, recall remained higher for those who referred to it at home, by 15 percentage points for diagnostic items and $>20$ percentage points for treatment items ( $13 \%$ all items).

One participant had a very high recall rate although he declared no further use of the PETD after the initial consultation. This demonstrates the usefulness of administering the PETD at the time of consultation. Subsequently referring to the worksheet, however, appears to further enhance recall. Owing to different learning styles and potentials of different patients, some clients will be highly influenced by the immediate PETD-related discussion that follows the history and physical examination, while others may need time to reflect on the new information provided. The PETD accommodates for both these learning styles. The analyses in which PETD use was an independent variable were performed twice, with the data for this participant and without. Findings of significance or otherwise did not depend on the presence of this participant.

Apart from assisting the patient, the PETD helps the clinician to remember which pain risk factors should/could be queried. It helps to guide the physician through often emotionally laden territories in a methodical, matter-of-fact manner. Physical, medical, ergonomic and psychosocial factors are given equal weight, and physicians do not need to initially emphasize one category over the other even though they may perceive there is a need to do so. The patient is told, "You tell me which of these factors are relevant to your case and I will do the same, and I will try to find you the particular help you need." The PETD can also be used as a communication tool among health care professionals engaged in caring for patients with chronic pain because it is a tangible, portable instrument that the patient can share. Future plans include uploading the PETD to an electronic tablet so that the clinician can 'write' directly on the screen and immediately e-mail the worksheet to the patient/client.

\section{Study limitations}

An obvious limitation to the present study was the small sample size. Almost one-half of the 84 patients who were eligible for the study could not be contacted (eg, did not reply to message left by the RA, telephone number no longer in service), and nine of the 46 who were contacted believed that the $1 \mathrm{~h}$ interview would be too long for them. Thirty-five patients consented to be interviewed, giving a recruitment rate of $41.7 \%$, and 29 patients completed the interview, for an overall response rate of $34.5 \%$. The difficulties in recruiting participants with a variety of disorders, including chronic diseases, owing to problems making initial contact with prospective participants are well documented (40-44). In a large study investigating oral health in adults $\geq 45$ years of age, Matthews et al (45) obtained a telephone interview response rate of $21 \%$. In 2007, Galea and Tracy (46) reported that participation rates for epidemiological studies had been declining during the previous 30 years, with even steeper declines in recent years. Our recruitment rate is, thus, consistent with many in the literature.

A further limitation was that all patients with chronic musculoskeletal pain in the principal author's practice received the PETD. Without a control group, it was not possible to compare the effectiveness of this approach to consultations in which the PETD was not used. The present study could be described as exploratory prospective research based on clinical practice experience.

In the present study, women were over-represented. The female:male ratio of 3:1 reflected the demographics of the physiatrist's practice and is consistent with the literature: Hayes et al (47) indicated that the female:male ratio among patients with fibromyalgia is $3.8: 1$.

\section{CONCLUSIONS}

The PETD is a promising, feasible and inexpensive tool that can be used by multiple health care professionals to deliver interactive diagnostic- and treatment-related information to their patients/clients experiencing persisting musculoskeletal pain. It emphasizes the concept of the involvement of pain risk factors in chronic musculoskeletal pain and can prompt clinicians to further discuss them as part of their therapeutic approach. Referring to the PETD after the initial consultation improves patients' recall of medical information, which is further enhanced by continued referral to the worksheet over the ensuing months.

ACKNOWLEDGMENTS: MMY was supported by a University of Ottawa (Ottawa, Ontario) Faculty of Medicine 2012 Summer Studentship. The authors thank Gloria Baker and Linda GreeneFinestone for editorial assistance, and are grateful to all of the patients who agreed to be interviewed about their experience with the Pain Explanation and Treatment Diagram.

DISCLOSURES: The authors have no conflicts of interest to declare. 


\section{APPENDIX 1}

\section{Telephone questionnaire}

\begin{tabular}{|c|c|c|c|}
\hline 1. Have you seen this form? (PETD) & Yes & \multicolumn{2}{|l|}{ No } \\
\hline 2. Can you show me the form? & Yes & \multicolumn{2}{|l|}{ No } \\
\hline 3. What did Dr F say about: & \multicolumn{3}{|c|}{ (Indicate if you needed to prompt the person) } \\
\hline a. Your causes of ergonomic pain & $\mathrm{N}$ correct & $\mathrm{N}$ causes & Prompt \\
\hline b. Your level of exercise & $\mathrm{N}$ correct & $\mathrm{N}$ causes & Prompt \\
\hline c. The quality of your sleep & $\mathrm{N}$ correct & $\mathrm{N}$ causes & Prompt \\
\hline d. Bad habits which would contribute to your pain & $\mathrm{N}$ correct / & $\mathrm{N}$ identified & Prompt \\
\hline e. What your problems are & $\mathrm{N}$ correct / & $\mathrm{N}$ identified & Prompt \\
\hline f. What your problems are not & $\mathrm{N}$ correct / & $\mathrm{N}$ identified & Prompt \\
\hline g. Other conditions in your life that can affect your & $\mathrm{N}$ correct / & $\mathrm{N}$ identified & Prompt \\
\hline
\end{tabular}

pain, and how

4. What did Dr F say about:

\section{a. The treatment for your ergonomic pain \\ b. The treatment for your level of exercise \\ c. The treatment to improve the quality of your sleep \\ d. Treatments for your bad habits}

5. Do you do the treatments:

6. Do the treatments help?

$\begin{array}{lll}\text { N correct / } & \text { N identified } & \text { Prompt } \\ \text { N correct / } & \text { N identified } & \text { Prompt } \\ \text { N correct / } & \text { N identified } & \text { Prompt } \\ \text { N correct / } & \text { N identified } & \text { Prompt } \\ \text { All the time } & \text { Partially } & \text { Not at all } \\ \text { All the time } & \text { Partially } & \text { Not at all }\end{array}$

In a visible place

Yes

Do you agree? If

not, why not?

No 
20. Uzzaman MM, Sinha S, Shaygi B, et al. Evaluation of patient's understanding and recall of the consent process after open inguinal hernia repairs. Int J Surg 2012;10:5-10.

21. Bernhard J, Aldridge J, Butow PN, et al. Patient-doctor agreement on recall of clinical trial discussion across cultures. Ann Oncol 2013;24:391-7.

22. McKinstry B, Watson P, Elton RA, et al. Comparison of the accuracy of patients' recall of the content of telephone and face-to-face consultations: An exploratory study. Postgrad Med J 2011;87:394-9.

23. Godwin Y. Do they listen? A review of information retained by patients following consent for reduction mammoplasty. Br J Plast Surg 2000;53:121-5.

24. Selic P1, Svab I, Repolusk M, et al. What factors affect patients' recall of general practitioners' advice? BMC Fam Pract 2011;12:141.

25. Ong LM, Visser MR, Lammes FB, et al. Effect of providing cancer patients with the audiotaped initial consultation on satisfaction, recall, and quality of life: A randomized, double-blind study. J Clin Oncol 2000;18:3052-60.

26. Müller-Schwefe G, Jaksch W, Morlion B, et al. Make a CHANGE: Optimising communication and pain management decisions. Curr Med Res Opin 2011;27:481-8.

27. Finestone HM, Singer L, Mayo NE, et al. The Pain Explanation and Treatment Diagram: A tool to enhance patient self-management of persistent pain. PM R 2012;4:456-8.

28. New Zealand Acute Low Back Pain Guide: Incorporating the Guide to Assessing Psychosocial Yellow Flags in Acute Low Back Pain. Wellington: Accident Compensation Corporation, 2004. <http:// accforum.org/forums/index.php?/topic/13972-new-zealand-acutelow-back-pain-guide/> (Accessed June 27, 2014).

29. Bolker BM. Ecological Models and Data in R. Princeton: Princeton University Press, 2008.

30. Crowder MJ. Beta-binomial ANOVA for proportions. J R Stat Soc C Appl Stat 1978;1:34-7.

31. R Core Team. R: A language and environment for statistical computing. Vienna: R Foundation for Statistical Computing, 2012.

32. Bolker B, R Development Core Team. Tools for general maximum likelihood estimation. R package version 1.0.5.2. 2012. $<$ https://r-forge.r-project.org/scm/viewvc.php/pkg/DESCRIPTION?vie $\mathrm{w}=$ markup\&revision $=109$ \& root $=$ bbmle $>$ (Accessed June 27, 2014).

33. Böhning D, Greiner M. Prevalence estimation under heterogeneity in the example of bovine trypanosomosis in Uganda. Prev Vet Med 1998;36:11-23.

34. Kravitz RL, Tancredi DJ, Grennan T, et al. Cancer Health Empowerment for Living without Pain (Ca-HELP): Effects of a tailored education and coaching intervention on pain and impairment. Pain 2011;152:1572-82.

35. LeFort SM. A test of Braden's Self-Help Model in adults with chronic pain. J Nurs Scholarsh 2000;32:153-60.

36. Flocke SA, Stange KC. Direct observation and patient recall of health behavior advice. Prev Med 2004;38:343-9.

37. Ford S, Fallowfield L, Hall A, et al. The influence of audiotapes on patient participation in the cancer consultation. Eur J Cancer 1995;31A:2264-9.

38. Higgins L, Ambrose P. The effect of adjunct questions on older adults' recall of information from a patient education booklet. Patient Educ Couns 1995;25:67-74.

39. Langdon IJ, Hardin R, Learmonth ID. Informed consent for total hip arthroplasty: Does a written information sheet improve recall by patients? Ann R Coll Surg Engl 2002;84:404-8.

40. Miller WR, Bakas T, Buelow JM, Habermann B. Research involving participants with chronic diseases: Overcoming recruitment obstacles. Clin Nurse Spec 2013;27:307-13.

41. Hunninghake DB, Darby CA, Probstfield JL. Recruitment experience in clinical trials: Literature summary and annotated bibliography. Control Clin Trials 1987;8(4 Suppl):6S-30S.

42. Pressler SJ, Subramanian RM, Shaw LE, Meyer K, Stoudemire I, Gradus-Pizlo I. Research in patients with heart failure: Challenges in recruitment. Am J Crit Care 2008;17:198-203.

43. Vernon H, Jansz G, Goldsmith CH, McDermaid C. A randomized, placebo-controlled clinical trial of chiropractic and medical prophylactic treatment of adults with tension-type headache: Results from a stopped trial. J Manipulative Physiol Ther 2009;32:344-51.

44. DeHertogh W, Vaes P, Devroey D, et al. Preliminary results, methodological considerations and recruitment difficulties of a randomised clinical trial comparing two treatment regimens for patients with headache and neck pain. BMC Musculoskelet Disord 2009;10:471-4.

45. Matthews DC, Brillant MG, Clovis JB, et al. Assessing the oral health of an ageing population: Methods, challenges and predictors of survey participation. Gerodontology 2012;29:e656-6.

46. Galea S, Tracy M. Participation rates in epidemiologic studies. Ann Epidemiol 2007;17:643-53.

47. Hayes SM, Myhal GC, Thornton JF, et al. Fibromyalgia and the therapeutic relationship: Where uncertainty meets attitude. Pain Res Manag 2010;15:385-91. 


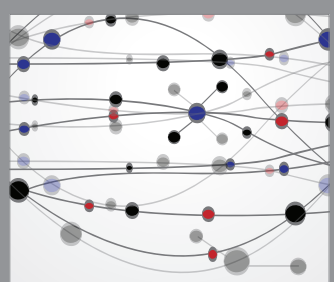

The Scientific World Journal
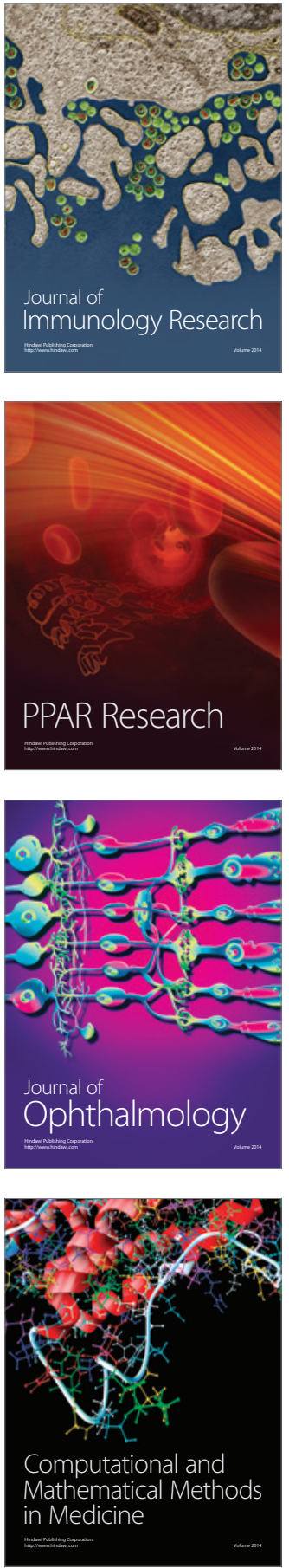

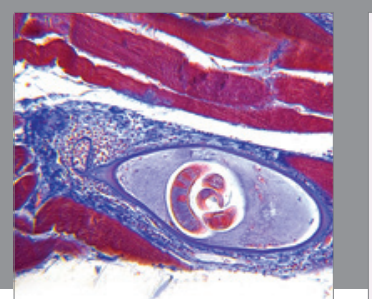

Gastroenterology Research and Practice

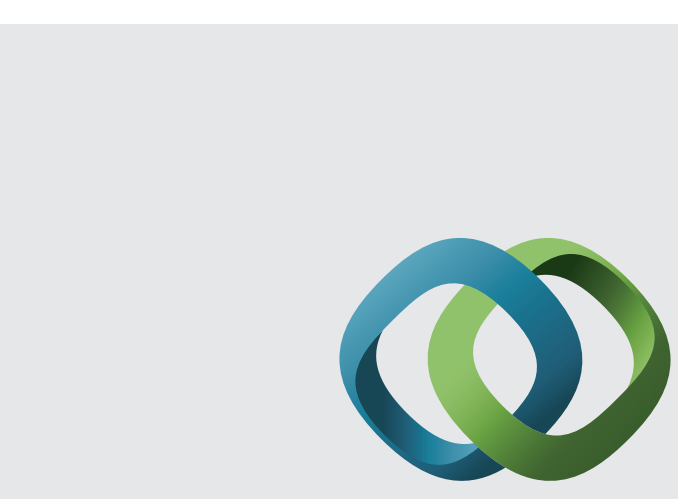

\section{Hindawi}

Submit your manuscripts at

http://www.hindawi.com
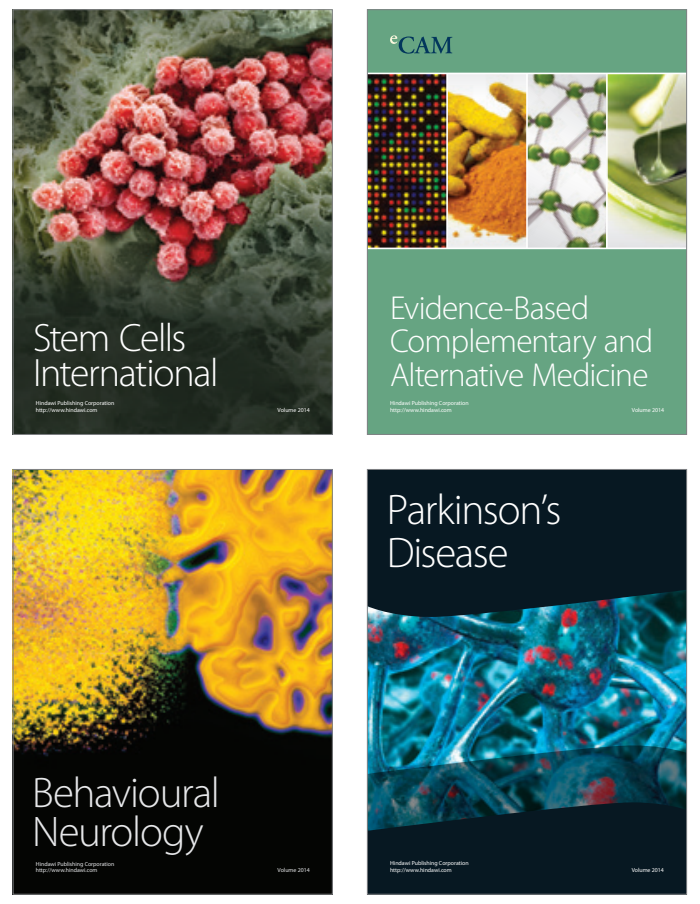
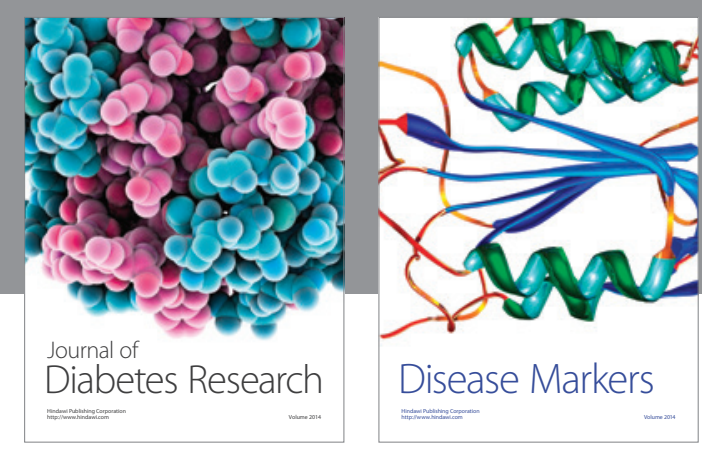

Disease Markers
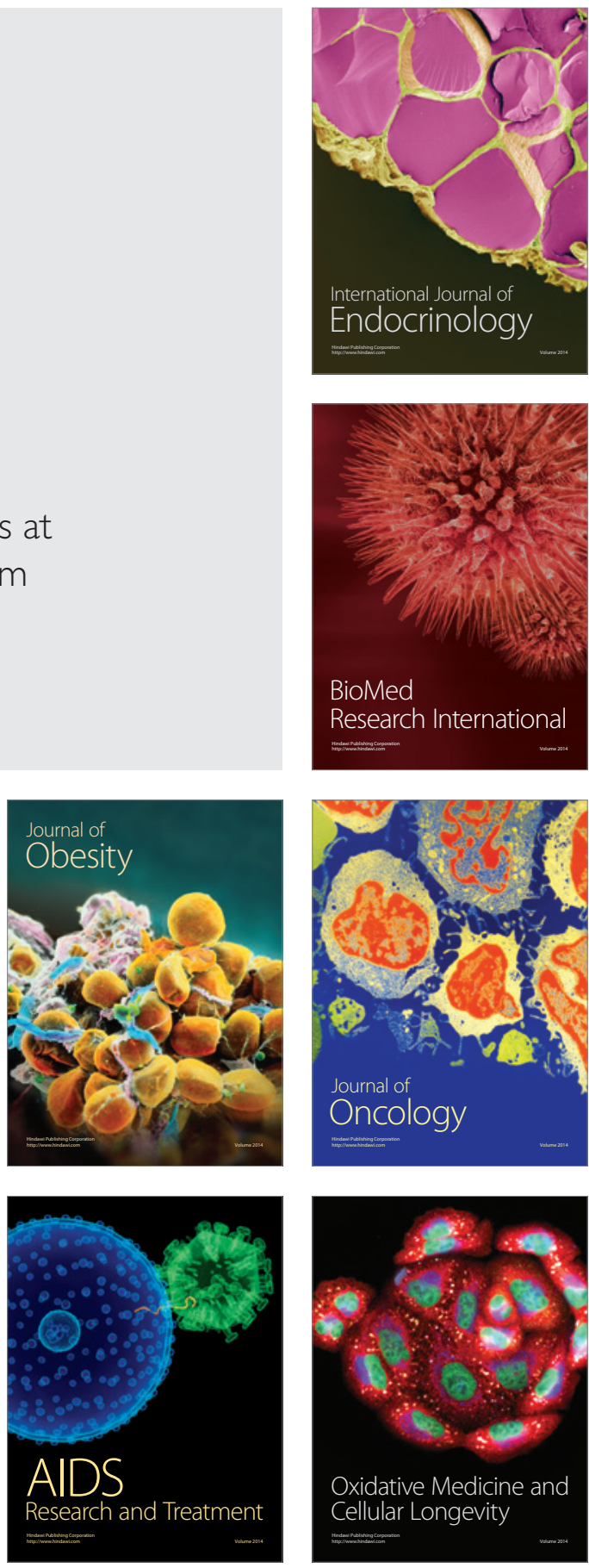